
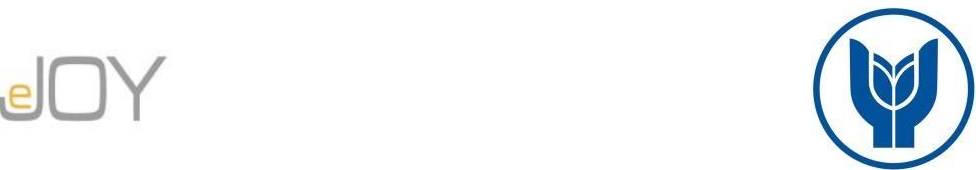

Dağl1, İ., Kösekahyaoğlu, L. / Journal of Yasar University, 2021, 16/63, 1237-1255

\title{
Bilim ve Teknoloji Politikaları Bağlamında Teknoloji-İşsizlik İlişkisi: Ampirik Bir İnceleme ${ }^{1}$
}

\section{Technology-Unemployment Relationship in the Scope of Science and Technology Policies: An Empirical Review}

İbrahim DAĞLI, Süleyman Demirel Üniversitesi, Türkiye, mribrahimdagli@gmail.com

Orcid No: 0000-0001-8199-821X

Levent KÖSEKAHYAOĞLU, Süleyman Demirel Üniversitesi, Türkiye, leventkosekahyaoglu@ sdu.edu.tr

Orcid No: 0000-0002-5466-5396

Öz: Bu makalenin amacı iki yönlüdür. Birinci amaç, teknolojinin istihdama yönelik etkilerini ele alan ve nicelik bakımından oldukça yetersiz olan makro düzeydeki ampirik literatüre katkıda bulunmaktadır. İkinci amaç, teknolojinin işsizliğe neden olacağına dair genel önyargl ve endişeye karşı nicel bir bulgu ile tartışmaya katkı sunmaktadır. Bu çalışmada, Sistem Genelleştirilmiş Momentler tahmincisi ile 22 Avrupa Birliği ülkesi ve Türkiye için 2005-2018 yıllarına ait verilerle teknoloji ve işsizlik ilişkisi analiz edilmiştir. Yapılan analiz sonucunda, genel önyargının aksine teknolojinin işsizlik üzerinde olumlu bir etkisinin olduğu fakat bu etkinin geçici bir etki olduğu ve ikinci yıldan itibaren kaybolduğu görülmüştür. Bu şekilde teknolojik gelişimin telafi mekanizmalarl sayesinde istihdam üzerinde olumsuz bir etki yapmadı̆̆ l ampirik olarak ortaya konulmuştur.

\section{Anahtar Sözcükler: Teknoloji, İssizlik, S-GMM, Teknolojik İssizlik, Teknoloji Politikası}

JEL Sinıflandirmast: L00, O30, J20

Abstract: The purpose of this paper is twofold. The first goal is to contribute to the empirical literature at the macro level, which is quite insufficient quantitatively, related to the impact of technology on employment. The second purpose is to contribute to the discussion with a quantitative finding regarding the general bias and concern that technology will cause unemployment In this study, technology and unemployment relationship has been analyzed with System Generalized Method of Moments estimator for the 22 European Union countries and Turkey with data for the years 2005-2018. As a result of the analysis, it has been observed that, contrary to the general prejudice, technology has a positive effect on unemployment, but this effect is temporary and disappears after the second year. In this way, it has been empirically demonstrated that technological development does not have a negative impact on employment thanks to compensation mechanisms.

Keywords: Technology, Unemployment, S-GMM, Technological Unemployment, Technology Policy

JEL Classification: L00, O30, J20

\section{Giriş}

Yapay zekâ ve makine öğrenmesi gibi birçok ardıl teknolojiyi tetikleyen ve aynı zamanda bu teknolojilerden beslenen bütünleşik teknolojiler, bu defa farklı bir döneme mi girdiğimizi sorgulatmaktadır. Daha önceden büyük oranla sanayi ve üretimle ilişkili olan teknolojik değişimler günümüzde gündelik hayatın vazgeçilmesi haline gelmiştir. Nesnelerin interneti ile birçok cihazın internet yoluyla birbirine bağlanması ve bu şekilde elde edilecek büyük veri ve bu verilerin yapay zekâ ile tekrar kullanımımıza sunulması günlük bir döngü haline gelmiştir. Netflix’de size seveceğiniz filmlerin önerilmesi, Google akademikte sizin ilginizi çekebilecek

\footnotetext{
${ }^{1}$ Bu çalışma Prof. Dr. Levent KÖSEKAHYAOĞLU danışmanlığında tamamlanan "Emek Piyasalarında Dönüşüm: Teknolojik Yeniliğin İstihdam ve İşsizlik Üzerindeki Etkileri” başlıklı İbrahim DAĞLI’ya ait doktora tezinden türetilmiştir.
} 
makalelerin önerilmesi, web sayfalarında gezerken almayı planladığınız bir ürünün reklamının gösterilmesi teknolojinin ne kadar içimizde olduğunun yalnızca basit bir göstergesidir.

Teknolojik değişim ve gelişimin toplumsal hayata yönelik etkileri düşünüldügünde hiç şüphesiz ilk akla gelenler arasında teknolojinin yol açabileceği işsizlik yer almaktadır. Otomasyon her geçen gün bir adım daha öteye geçerken makinelerin devraldığı işlerde çalışan insanların işsiz kalacağı endişesi 1800'lü yıllarda başlayan Luddist eylemleri çağrıştırmaktadır. 1930'da Keynes'in dile getirdiği ve geleceğin hastalığı olarak bahsettiği teknolojik işsizlik dalgası, tarihin hiçbir döneminde belirgin olarak yaşanmamıştır. Bununla birlikte teknolojinin üstel bir hızla artışı Endüstri 4.0 ile birlikte daha çok hissedilmeye başlamıştır. Endüstri 4.0 sürecinde ortaya çıkan akıllı fabrikalar ve akıllı üretim süreci teknolojik işsizlik kavramını yeniden alevlendirmiştir.

Teknolojik değişimin etkisiyle artan verimlilik ve azalan maliyetler karşısında makinelerin insanlardan devraldığı işler yerine, yeni ortaya çıkacak işlerin günümüz işgücü yapısı için nitelik ve nicelik bakımından ne kadar uyumlu olduğu devam eden bir tartışma konusudur. $\mathrm{Bu}$ tartışmada genellikle teknolojinin etkisiyle artan verimlilik ve yeni ortaya çıkan sektörler ve meslekler ihmal edilmekte ve bir insanın yaptığı işin otomasyona uğraması sonucu o işçinin yeni ortaya çıkan işgücünde rol alması ihtimali göz ardı edilmektedir. İlk Sanayi Devrimi’nden bugüne dek devam eden teknolojinin yaratabileceği potansiyel işsizlik tartışması halen somut bir zemine oturtulamamıştır.

Bu çalışmada da teknoloji ve işsizlik ilişkisi ampirik bir analiz ile ele alınmıştır. Bu konuda literatürde yapılmış çalışmaların tamamına yakını mikro düzeyde yapılmış modellemelerden oluşmaktadır. Bu çalışmanın makro düzeyde bir modelleme ve analiz içermesi mevcut diğer çalışmalardan farkını yansıtmaktadır. Ayrıca teknoloji değişkeni olarak üçlü patent ailesi değişkeninin kullanımına dair örnekler literatürde çok azdır. Üçlü patent ailesi değişkenin kullanımı, çalışmanın bir diğer katkısıdır. Çalışmada teknolojinin hem uzun dönemli hem kısa dönemli etkisinin değerlendirilmiş olması literatüre sağladığı katkılardan bir diğeri olmuştur.

Sistem Genelleştirilmiş Momentler tahmincisi (S-GMM) yöntemi ile yapılan panel veri analizi, geniş bir ülke (22 Avrupa Birliği ülkesi ve Türkiye) grubu genelinde ve 10 kontrol değişkeni ile kapsamlı bir modelle yapılmıştır. Analiz 2005-2018 yılları verilerini kapsamaktadır. Bu çalışmanın ilk bölümünde, kısıtlı olduğuna değinilen makro düzeydeki ampirik literatür incelenmiştir. Çalışmanın devamında, yöntem, değişkenler ve modele ilişkin bilgiler verilmiştir. S-GMM analiz bulgularının paylaşıldığı bölümün ardından elde edilen sonuçlar ve bu sonuçlara ilişkin politika önerileri ile çalışma son bulmuştur. 


\section{Makro Düzeydeki Ampirik Çalışmalar}

İktisat yazınında teknoloji ve işsizlik ilişkisini analiz eden birçok ampirik çalışma bulunmaktadır. Ancak bu çalışmaların önemli bir çoğunluğunun mikro düzeyde çalışmalar olduğu (firma ve sektörel) görülmektedir. Makro düzeyde çalışmaların sayıca az olması, bu düzeyde yapılacak analizlerin birtakım kısıtlarından kaynaklanmaktadır. Bu konudaki temel kısıtlar: teknoloji değişkeninin seçilmesindeki belirsizlik, literatürde faydalanılabilecek çalışmanın çok az sayıda olması, kontrol değişkeni seçimindeki belirsizlikler, araç değişkenleri seçiminde kullanılacak parametrelerdeki belirsizlikler ve mevcut çalışmaların önemli bir çoğunluğunda kesin bulgulara ulaşılamamış olmasıdır. Tablo 1'de literatürde mevcut ve makro düzeyde yapılmış ampirik çalışmalara yer verilmiştir.

Tablo 1. Makro Düzeydeki Ampirik Çalışmalar

\begin{tabular}{|c|c|c|c|c|c|c|}
\hline \multirow[t]{2}{*}{ YAZARLAR } & \multicolumn{2}{|c|}{ ETKİLENEN } & \multicolumn{4}{|c|}{ TESPITT EDILLEN İLISSKİ YÖNÜ } \\
\hline & İstihdam & İşsizlik & Poz.(+) & Neg.(-) & İlişkisiz & Belirsiz \\
\hline Sinclair (1981) & $\mathrm{X}$ & & & & & $\mathrm{X}$ \\
\hline Layard ve Nickell (1985) & $\mathrm{X}$ & & $\mathrm{X}$ & & & \\
\hline Pini (1995) & $\mathrm{X}$ & & & $\mathrm{X}$ & & \\
\hline Vivarelli (1995) & $\mathrm{X}$ & & $\mathrm{X}$ & $\mathrm{X}$ & & \\
\hline Simonetti vd. (2000) & $\mathrm{X}$ & & & $\mathrm{X}$ & & $\mathrm{X}$ \\
\hline Tancioni ve Simonetti (2002) & $\mathrm{X}$ & & & & & $\mathrm{X}$ \\
\hline Feldmann (2013) & & $\mathrm{X}$ & $\mathrm{X}$ & & & \\
\hline Evangelista vd. (2014) & $\mathrm{X}$ & & $\mathrm{X}$ & & $\mathrm{X}$ & \\
\hline Aguilera ve Barrera (2016) & $\mathrm{X}$ & & $\mathrm{X}$ & & & \\
\hline Gregory vd. (2016) & $\mathrm{X}$ & & $\mathrm{X}$ & & & \\
\hline Matuzeviciute vd. (2017) & & $\mathrm{X}$ & & & $\mathrm{X}$ & \\
\hline Cang (2017) & $\mathrm{X}$ & & & & $\mathrm{X}$ & \\
\hline Krouise (2018) & & $\mathrm{X}$ & $\mathrm{X}$ & & & \\
\hline
\end{tabular}

Teknolojinin istihdama etkilerine yönelik en eski çalışmalardan birisi olarak kabul edilen Sinclair'in (1981) çalışmasında ABD için teknolojinin istihdamı hangi yönde etkileyebileceğine dair net bir bulguya ulaşılamamıştır. Layard ve Nickell (1985) ise bu etkinin tahmini işgücü talebi esnekliğinden dolayı ihmal edilebilir düzeyde olduğunu tespit etmiştir.

Pini (1995), teknolojinin kısa vadede olumsuz etki yapabilme olasılığına karşın uzun vadede bu etkinin ihracat yoluyla telafi edilebileceğini savunmaktadır. Vivarelli (1995), İtalya ve ABD için yaptığı zaman serisi analizinde teknoloji ve işsizlik ilişkisinin, İtalya için negatif ancak ABD için pozitif olduğu sonucuna ulaşmıştır. Bu hususu, İtalya'da süreç yeniliği etkisinin, ABD'de ise ürün yeniliği etkisinin baskın olmasına bağlamaktadır. 
Simonetti vd. (2000), ABD, İtalya, Fransa ve Japonya için yaptı̆̆ı analizde, süreç yeniliğinin istihdam üzerinde olumsuz etkisi olduğunu tespit etmiştir. Bununla birlikte telafi mekanizmalarının istihdam üzerindeki etkilerinin ülkelere göre değişkenlik gösterdiği sonucuna ulaşmıştır. Tancioni ve Simonetti (2002), İngiltere ve İtalya ülkelerinde teknolojinin etkilerine yönelik telafi mekanizmalarının istihdam üzerindeki etkilerini ele almıştır. İngiltere'nin süreç yeniliği karşılığında iki kat daha duyarlı olduğu sonucuna ulaşılmış ancak teknolojinin genel etkisine yönelik sonuç belirsiz kalmıştır.

Feldmann'in (2013) 21 sanayi ülkesine yönelik yaptığı panel veri analizinde, teknolojinin istihdam üzerinde olumsuz bir etki yaptığı tespit edilmiştir. Ancak bu etkinin kısa dönemli (3 y1l) geçici bir etki olduğu ve üçüncü yıldan sonra kendiliğinden ortadan kalktığı görülmüştür. Evangelista vd. (2014), Avrupa Birliği’ne ülkelerine yönelik yaptı̆̆ı analizde teknolojinin etkilerini bilgi ve iletişim teknolojileri bazında ele almıştır. Hizmet sektörü dışında teknoloji ve istihdam ilişkisine rastlanmayan çalışmada, hizmet sektöründe bilgi ve iletişim teknolojilerinin istihdam üzerinde olumlu etki yaptığı görülmüş̧ür.

Aguilera ve Barrera (2016), teknolojik yönden önde olan Latin Amerika ülkeleri için yaptığı analizde teknoloji gelişiminin henüz işsizliği arttıracak düzeyde olmadığını tespit etmiştir. Hatta bu ülkelerde teknolojinin az miktarda da olsa istihdam üzerinde olumlu etki yaptığ görülmüştür. Gregory vd. (2016) 27 Avrupa Birliği ülkesine yönelik yaptığı analizde, teknolojik değişimin istihdama yönelik olumlu etkileri olduğunu tespit etmiştir. Analiz döneminde bu olumlu katkının yaklaşık 11,6 milyon yeni iş sağladığı sonucuna ulaşılmıştır. Yazarlar bu olumlu etkiyi teknoloji etkilerinin telafi mekanizmalarıyla fazlaca dengelenmiş olmasına bağlamaktadır.

Matuzeviciute vd. (2017) 25 Avrupa ülkesinde teknolojinin etkilerine yönelik bir panel veri analizi yapmıştır. İki farklı teknoloji değişkeni ile tekrar edilen analizin her ikisinde de teknoloji ve işsizlik arasında istatistiki bir ilişkiye rastlanmamıştır. Cang (2017) ABD eyaletlerine yönelik yaptığı çalışmada, teknoloji ve işsizlik ilişkisine dair genel bir etkiye ulaşamamıştır. Bununla birlikte daha az teknoloji meraklısı olan eyaletlerin teknolojik değişimden kaynaklanan iş kaybından daha fazla etkilendiği sonucuna ulaşmıştır.

Krousie (2018) ABD eyaletlerine yönelik ve Cang (2017) tarafından yapılan çalışmanın devamı niteliğinde bir çalışma yapmıştır. Bu defa ABD eyaletleri için teknolojik değişim ile işsizlik arasında pozitif yönlü bir ilişkiye rastlanmıştır. Teknolojinin işsizliği arttırdığı sonucuna ulaşılmasına rağmen bu etkinin çok küçük düzeyde olduğu belirlenmiştir. 


\section{Yöntem: Neden Dinamik Panel Analizi?}

Dinamik modeller, model içerisinde değişkenlerin gecikmeli değerlerine yer verdiğinden statik modellerden farklıdır. Ancak bağımlı değişkene ait gecikmeli değerin model içerisinde bağımsız değişken olarak kullanılması temel varsayımlardan olan dışsallık ile çelişmekte ve muhtemel bir içsellik durumuna işaret etmektedir. Dolayısıyla en küçük kareler yöntemi (EKK) ile yapılacak bir analizde birim ve zaman etkilerinin yanı sıra içsellik etkisi de ihmal edilmiş olacaktır. Ayrıca bağımlı değişkenin gecikmeli halinin model içerisinde gözlenemeyen etkilerle korelasyonlu olması rassal etkiler modelinin kullanılması durumunda da önemli bir varsayımı ihlal edecektir (Baltagi 2005, 135-139).

Bununla birlikte bağımsız değişkenler ile birim etkilerin korelasyonlu olmasına izin veren sabit etkiler tahmincilerinin dinamik modellerde kullanılması mümkündür. Bunun nedeni, sabit etkiler modelinde birim etkinin grup içi dönüşüm yoluyla ortadan kaldırılmasıdır. Gölge değişkenli EKK ile de sabit etkiler modeliyle aynı sonuca ulaşılması mümkün olacaktır. Ancak bu durumda "Nickell Sapması"ndan kaçınmak için birim ve zaman boyutlarının uyumlu olmasına dikkat edilmesi gerekmektedir. Nickell'e (1981) göre birim boyutunun zaman boyutundan büyük olması bu sapmaya neden olabilecektir. $\mathrm{Bu}$ analizde kullanılacak veri setinde birim boyutunun zaman boyutundan fazla olduğu ve dolayısıyla gölge değişkenli EKK kullanılması durumunda Nickell Sapması oluşabileceği değerlendirilmektedir.

Dinamik panel veri modelleri için bağımsız değişkenler ile birim etkilerin korelasyonlu olmasına izin veren birinci farklar yöntemlerinin kullanılması yaygındır. Bu yöntemde yaygın olarak kullanılan tahmincilerden bazıları: Anderson ve Hsiao (1982) tahmincisi, Arellano ve Bond (1991) Genelleştirilmiş Momentler (GMM) tahmincisi, Arellano ve Bover (1995)/ Blundell ve Bond (1998) Sistem Genelleştirilmiş Momentler tahmincisi (S-GMM) ve Keane ve Runkle (1992) tahmincileridir.

Anderson ve Hsiao (1981) ve Arellano ve Bond (1991) tarafından geliştirilen GMM tahmincisinde, gecikmeli değişkenlerden geçerli olanların tamamı araç değişken olarak kullanılmaktadır. $\mathrm{Bu}$ şekilde bütün moment koşullarının yerine getirilmesinin mümkün olabileceği savunulmaktadır. GMM iki aşamalı bir tahmincidir. Birinci aşamada, birinci fark modeli araç değişkenlerle dönüştürülmekte, ikinci aşamada, dönüştürülen bu model genelleştirilmiş en küçük kareler yöntemi ile tahmin edilmektedir (Tatoğlu 2018, 129).

Arellano ve Bover (1995) ise bu dönüşümün yetersiz kaldığı gerekçesi ile alternatif bir dönüşüm modeli önermiştir. Helmert dönüşümü kullanarak birinci farkların alınmasına alternatif olarak ortogonal sapmaların daha verimli sonuçlar verdiği ortaya konulmuştur (Arellano ve Bover, 1995: 41-42). Arellano ve Bover (1995) ve Blundell ve Bond (1998) araç 
değişkenlerin birinci farklarının sabit etkilerle korelasyonsuz olduğuna dair ilave bir varsayımda bulunarak Arellano ve Bond (1991) modelini geliştirmiştir. Yeni geliştirilen SGMM yönteminde, orijinal ve dönüştürülmüş olmak üzere iki eşitlikli bir sistem ortaya konulmuştur (Roodman, 2009b: 86-87). Bu yöntem daha fazla araç değişken kullanılmasını ve bu sayede etkinliğin artmasını sağlamaktadır. Bu nedenle panel veri analizlerinde S-GMM kullanılması önerilmektedir (Arellano ve Bover 1995; Bogliacino ve Vivarelli 2012; Bond vd. 2001; Hauk ve Wacziarg 2009).

Bağımlı değişkenin gecikmeli olarak bağımsız değişkenler arasında yer aldığı model genel olarak aşağıda yer alan eşitlikte olduğu gibi gösterilmektedir (Hsiao 2003, 69).

$$
\begin{gathered}
y_{i t}=\gamma y_{i, t-1}+\beta^{\prime} x_{i t}+\alpha_{i}^{*}+\lambda_{t}+u_{i t}, \\
\mathrm{i}=1, \ldots, \mathrm{N}, \quad \mathrm{t}=1, \ldots, \mathrm{T},
\end{gathered}
$$

Modelde yit bağımlı değişkeni ve yi,t-1 bağımlı değişkenin gecikmeli değerini, xit sabit terimle birlikte açıklayıcı değişkenlerin $\mathrm{K} \times 1$ vektörünü, $\beta \mathrm{K} \times 1$ sabitlerin vektörünü, $\alpha i *$ gözlenemeyen bireysel etkileri, $\lambda t$ gözlenemeyen zamana özgü etkileri, $u i t$ hata terimini ifade etmektedir.

Asimptotik varyans hesaplamaları ve Monte Carlo simülasyonları S-GMM'nin klasik GMM'e göre daha verimli sonuçlar ortaya koyduğunu göstermiştir (Blundell ve Bond 1998, 116). Blundell vd. (2000) S-GMM ile ilgili yaptıkları çalışmada, bu yöntemin tahminlerin hassasiyetini arttırmasının yanı sıra sonlu örneklem sapmasını da azalttığını tespit etmişlerdir. Ayrıca Cobb- Douglas üretim fonksiyonu ile yaptıkları analizde S-GMM yönteminin GMM yönteminin birçok dezavantajını giderdiğini ortaya çıkarmışlardır.

Teknoloji ve istihdam değişkenleri kullanılarak yapılacak bir analizde içsellik en temel problemlerden birisidir. Bu değişkenlerle yapılan analizlerde içselliğin en önemli nedeni, ölçüm hataları ve gözlenemeyen etkilerin varlığıdır (Heijs vd. 2019, 4). Bununla birlikte zamana bağlı olarak değişmeyen ülke karakteristikleri, açıklayıcı değişkenlerle korelasyonlu olabilmektedir (Mileva 2007, 1).

S-GMM yöntemi; küçük zaman boyutuyla birlikte büyük birim boyutu içeren, içsellik problemi olan bağımsız değișkenler, değişkenler arasında otokorelasyon ve değişen varyans problemi olan durumlar için geliştirilmiştir (Roodman 2009b, 86). Özellikle zaman boyutunun birim boyutundan büyük olduğu modellerde S-GMM yöntemiyle daha verimli sonuçlar elde edildiği görülmüştür (Blundell ve Bond 1998, 133).

Roodman (2009b) GMM tahmincilerinin genel olarak şu özellikleri taşıan analizler için dizayn edildiğini belirtmektedir:

\section{- “Zaman boyutu küçük ve ülke/ birim boyutu daha büyük olan panel verileri,}


- $\quad$ Doğrusal bir fonksiyonel ilişki,

- $\quad$ Dinamik bir bă̆ımlı değişken (Kendi geçmiş değerlerinden etkilenen),

- Tamamen dişsal olmayan bağımsız değişkenler (Hata teriminin geçmiş ve cari dĕgerleriyle korelasyonlu),

- $\quad$ Sabit bireysel etkiler,

- Değişen varyans ve otokorelasyon varlığı”.

Bu çalışmada kullanılacak modelin birim boyutu 23 ve zaman boyutu 13'dür. İçsellik başta olmak üzere yukarıda ayrıntıları verilen temel varsayımların ihlali ve diğer modellere göre sağladığı üstünlükler nedeniyle bu çalışmada S-GMM yöntemi tercih edilmiştir.

\section{Veri Seti ve Değişkenler}

$\mathrm{Bu}$ analizde Türkiye ve yirmi iki AB ülkesine ait 2005-2018 yılı verileri kullanılmıştır. AB ülkelerinden bazıları veri eksikliği nedeniyle kapsam dışında tutulmuştur². Tablo 2'de gösterilen değişkenlerden Sendikalaşma Oranı OECD Stat veri tabanından, Ücret Pazarlığı Koordinasyonu Visser'den (2019) ve geriye kalan diğer tüm değişkenler OECD Data veri tabanından alınmıştır. Analizde tüm değişkenlerin (k hariç $\left.{ }^{3}\right)$ doğal logaritmaları kullanılmıştır.

Tablo 2. Değişkenler ve Beklenen Korelasyon

\begin{tabular}{|c|c|c|c|c|}
\hline \multirow{2}{*}{\multicolumn{2}{|c|}{ Değişkenler }} & \multirow[t]{2}{*}{ Kaynak } & \multicolumn{2}{|c|}{$\begin{array}{c}\text { Beklenen } \\
\text { Korelasyon }\end{array}$} \\
\hline & & & $(+)$ & $(-)$ \\
\hline Bağımlı & İşsizlik Oranı & OECD Data & $\mathrm{X}$ & $\mathrm{X}$ \\
\hline Bağımsız & Üçlü Patent Ailesi & OECD Data & $X$ & $X$ \\
\hline \multirow{10}{*}{ Kontrol Değişkenleri } & GSYH (Gayri Safi Yurtiçi Hasıla) & OECD Data & & $\mathrm{X}$ \\
\hline & Kamu İşsizlik Harcaması & OECD Data & $\mathrm{X}$ & \\
\hline & Vergi Takozu & OECD Data & $\mathrm{X}$ & $\mathrm{X}$ \\
\hline & TÜFE (Tüketici Fiyat İndeksi) & OECD Data & $\mathrm{X}$ & $\mathrm{X}$ \\
\hline & Sendikalaşma Oranı & OECD Stat & $\mathrm{X}$ & \\
\hline & Doğrudan Yabancı Sermaye Girişi & OECD Data & & $\mathrm{X}$ \\
\hline & Doğrudan Yabancı Sermaye Çıkışı & OECD Data & $\mathrm{X}$ & $\mathrm{X}$ \\
\hline & Reel Faiz Oranı & OECD Data & $\mathrm{X}$ & \\
\hline & Reel Döviz Kuru & OECD Data & $\mathrm{X}$ & \\
\hline & Ücret Pazarlığı Koordinasyonu & Visser (2019) & & $\mathrm{X}$ \\
\hline
\end{tabular}

$\mathrm{Bu}$ çalışmada, bağımlı değişken olarak işsizlik oranı, teknolojik yenilik değişkeni olarak patent sayıları kullanılmıştır. Patent sayısı olarak Feldmann (2013) ve Matuzeviciute vd. (2017)

\footnotetext{
${ }^{2}$ Türkiye ile birlikte analize dahil edilen AB ülkeleri: Almanya, Avusturya, Belçika, Çek Cumhuriyeti, Estonya, Finlandiya, Fransa, Hollanda, İngiltere, İrlanda, İspanya, İsveç, İtalya, Letonya, Litvanya, Lüksemburg, Macaristan, Polonya, Portekiz, Slovakya, Slovenya ve Yunanistan'dir.

${ }^{3}$ k değiş̧keninde 1 ile 5 arasında değişen sayılar koordinasyon türünü vermektedir. Ayrıntısı değiş̧kenlerin açıklamasında verilmiştir.
} 
tarafindan yapılan makro analizlerde kullanılan Üçlü Patent Ailesi (TPF-Triadic Patent Family) patent sayıları tercih edilmiştir.

Patent sınıflandırması seçiminde, analiz kapsamındaki tüm ülkelerin verileri ile karşılaştırabilme imkânı sağlayan ve teknik, coğrafi veya ulusal mevzuat farklılıklarından arındırılmış olan bir seçim yapılmasına özen gösterilmiştir. Bu bağlamda seçilen TPF dünya çapında en büyük üç patent ofisinde ${ }^{4}$ tanınan aynı yeniliğe ait patentleri göstermektedir.

Kontrol değişkeni olarak; Gayri Safi Yurtiçi Hasıla (GSYH), kamu işsizlik harcaması, vergi takozu, tüketici fiyat endeksi (TÜFE), sendikalaşma oranı, doğrudan yabancı sermaye (DYS) girişleri ve çıkışları, reel faiz oranı, reel döviz kuru ve ücret pazarlığı koordinasyonu kullanılarak kapsamlı ve geniş bir model kurulmuştur.

Literatüre göre DYS girişlerinin işsizlik oranını azaltması beklenmektedir (Abor ve Harvey 2008; Chang 2007; Sharma ve Cardenas 2019). DYS çıkışları için ise literatürde kabul görmüş ortak bir sonuç yoktur. DYS çıkışlarının işsizlik üzerinde arttırıcı etkisi (Driffield vd. 2009; Elia vd. 2009; Hijzen vd. 2011) veya azaltıcı etkisi olduğu sonucuna ulaşan çalışmalar (Barba Navaretti vd. 2010; Federico ve Minerva 2008; Masso vd. 2008) mevcuttur.

İşsizlik ve büyüme ilişkisini ele alan ve “Okun Yasası” olarak bilinen Okun’un (1962) çalışmasının geçerliliğini test eden birçok çalışma bulunmaktadır. Literatürün önemli bir çoğunluğu ters yönlü bu ilişkiyi doğrulamaktadır (Adanu 2005; Kangasharju vd. 2012; Lee 2000; Pierdzioc vd. 2011; Sögner 2001; Sögner ve Stiassny 2002).

Vergi takozu ücretlerdeki vergi ve sigorta primi yükünü ifade etmektedir. Bir işçinin işverene maliyeti ile işçinin ele geçen net ücreti arasındaki farkın, işçinin işverene maliyetine oranı olarak hesaplanmaktadır. Vergi takozunun işsizlik üzerindeki etkisi ise ülkelerin ekonomik yapılarına göre değişiklik gösterebilmektedir.

Kamu işsizlik harcaması geçici olarak işsiz kalanlara yönelik yapılan nakdi yardımlardır. Yardımların artmasının işsizlik oranını da arttıracağı değerlendirilmektedir (Fraile ve Ferrer 2005; Nickell vd. 2005; Onodugo vd. 2017).

Tüketici fiyat endeksi, enflasyonun temel göstergesidir. Enflasyonun işsizlikle ilişkisi öncelikle orijinal Phillips (1958) eğrisinde nominal ücret artışları ile işsizlik arasında ters yönlü bir ilişki olarak ortaya konulmuştur. Daha sonra Samuelson ve Solow (1960) tarafindan modifiye edilmiş Philips eğrisinde işsizlik ve enflasyon arasında ters yönlü bir ilişki bulunmuştur.

\footnotetext{
${ }^{4}$ ABD Patent Ofisi, Japonya Patent Ofisi ve Avrupa Patent Ofisi
} 
Sendikalaşma oranı, toplu pazarlık kapsamı ve ücret pazarlığı koordinasyonu, ücret pazarlığı sisteminin en temel özelliklerini taşımaktadır (Feldmann 2003, 1112). Sendikalaşma oranı, sendikaya üye olan işçilerin tüm işgücü içindeki payını göstermektedir. Bu oran işsizliği iki şekilde etkileyebilir: birincisi daha yüksek ortalama ücretler, ikincisi daha sıkı bir ücret yapısıdır (Baccaro ve Rei 2007, 538). Yapılan ampirik çalışmaların birçoğunda yüksek sendikalaşmanın işsizliği arttırdığı sonucuna ulaşılmıştır (Baccaro ve Rei 2007; Blanchard ve Wolfers 2000; Vandaele 2006).

Reel faiz oranlarındaki artışın yatırımları ve dolayısıyla işgücüne olan talebi azaltması beklenmektedir. Reel döviz kuru şoku ise yerli üretimi fiyat konusunda daha az rekabetçi kılacağından işsizliği arttırabilecektir (Frenkel ve Ros 2006; Bakhshi ve Ebrahimi 2016).

Ücret pazarlığı koordinasyonu ücret pazarlıklarından daha düşük ücretlerin ortaya çıkmasını sağlamaktadır. Literatürde ücret pazarlığı koordinasyonu ve işsizlik arasındaki ters yönlü ilişki doğrulanmaktadır (Flanagan 1999; Soskice 1990).

\section{Model ve Tanımlayıcı İstatistikler}

Dinamik panel veri analizi için çalışmanın modeli şu şekilde kurulmuştur:

$$
\begin{gathered}
u_{i, t}=\beta_{1} u_{i, t-1}+\beta_{2} g_{i, t}+\beta_{3} i h_{i, t}+\beta_{4} v t_{i, t}+\beta_{5} f i_{i, t}+\beta_{6} s_{i, t}+\beta_{7} s g_{i, t}+\beta_{8} s c_{i, t}+ \\
\beta_{9} f_{i, t}+\beta_{10} d_{i, t}+\beta_{11} k_{i, t}+\beta_{12} p_{i, t}
\end{gathered}
$$

$u$ bağımlı değişken olarak işsizlik oranını (\%),

$g$ gayrisafi yurt içi hasılayı (nominal kişi başı USD),

ih kamu işsizlik harcamasını (\% GSYH),

$v t$ vergi takozunu (\% kişisel gelir),

fe tüketici fiyat endeksini $(2015=100)$,

$s$ sendikalaşma oranını (sendika üyesi işçiler/tüm işçiler),

$s g$ doğrudan yabancı sermaye girişini (\% GSYH),

$s c ̧$ doğrudan yabancı sermaye çıkışını (\% GSYH),

$f$ reel faiz oranın1,

$d$ reel döviz kurunu (ulusal para/ USD),

k ücret pazarlığı koordinasyonunu (5-Merkezi pazarlığa dayalı maks. ve min. ücret oranlarl, 4-Hükümet koordinasyonlu veya koordinasyonsuz büyük kuruluşlarla merkezi pazarliğa dayalı ücret normları, 3-Merkezi pazarlığa dayalı müzakere esaslarl, 2-Karışık sanayi veya firma bazlı pazarlık, zayıf hükümet koordinasyonu, 1-Büyük ölçüde bireysel firmalarla sınırlı parçalı pazarlıklarl),

$p$ üçlü patent ailesine dahil patent sayısını (1 milyon kişi başına) temsil etmektedir. 
Modelin kurulmasında, Feldmann (2013) ve onu takip eden Matuzeviciute vd.'nin (2017) çalışmalarından yararlanılmıştır. Modelde kullanılan değişkenlerin tanımlayıcı istatistik tablosu Tablo 3'de verilmiştir.

Tablo 3. Tanımlayıcı İstatistik Tablosu

\begin{tabular}{ccccc}
\hline Değişken & Ort. & S. Sapma & Min. & Maks. \\
\hline İşsizlik & 2,079169 & 0,4313951 & 0,8080452 & 3,312991 \\
\hline GSYH & 10,42949 & 0,3886476 & 9,375476 & 11,62366 \\
\hline TÜFE & 4,539671 & 0,1137346 & 3,808882 & 4,93663 \\
\hline Vergi Takozu & 3,726437 & 0,1407823 & 3,334971 & 4,026897 \\
\hline Reel Döviz Kuru & 0,3968252 & 1,374612 & $-0,6936033$ & 5,640215 \\
\hline Reel Faiz & 2,071225 & 3,125192 & $-0,695$ & 19,82847 \\
\hline Ücret Pazarlığ1 & 2,458333 & 1,343627 & 1 & 5 \\
\hline DYS Girişi & 3,739803 & 0,6939563 & 2,31051 & 5,860215 \\
\hline DYS Çıkış1 & 3,068822 & 1,306458 & $-0,544307$ & 6,058159 \\
\hline İşsizlik Harcaması & $-0,3314892$ & 0,8863415 & $-2,764621$ & 1,268355 \\
\hline Sendikalaşma & 3,282843 & 0,7018318 & 1,842928 & 4,325456 \\
\hline Patent & 2,15751 & 1,771701 & $-6,288879$ & 4,682034 \\
\hline
\end{tabular}

\section{Bulgular, Yorumlanması, Sağlamlık Testleri ve Tartışmalar}

Analiz kısmında kullanılan S-GMM yöntemi için Roodman (2009b) tarafından önerilen "xtabond2" komutu kullanılmıştır ve analiz sonuçları Tablo 4'de verilmiştir. S-GMM yönteminde iki aşamalı tahmincilerden elde edilen sonuçların aşağı doğru sapmalı olduğu bilinmektedir. $\mathrm{Bu}$ nedenle iki aşamalı varyans kovaryans matrisi için önerilen Windmeijer (2005) örnek düzeltmesi ile dirençli tahminciler elde edilmiştir. S-GMM analizlerinde türetilen araç değişkenlerin sayısının gözlem sayısına yakın veya fazla olması sapmalı tahminlere neden olabilecektir. $\mathrm{Bu}$ nedenle analizde araç değişken sayılarının gözlem sayısına yakınlaşması gözetilmiş ve "collapse" opsiyonu kullanılarak araç değişken sayısı azaltılmıştır. Ayrıca analizde birinci farklar yönteminin neden olduğu veri kaybını azaltmak maksadıyla birinci farklar yerine Arellano ve Bover (1995) tarafindan önerilen "ortogonal sapmalar" kullanılmıştır. Bu yöntemde cari dönemden bir önceki dönemin farkı yerine, değişkenin tüm gelecek değerlerinin ortalamasının farkı kullanılmaktadır (Tatoğlu 2018, 136).

Tablo 4. S-GMM Tahmin Sonuçları

\begin{tabular}{|c|c|c|c|c|c|c|}
\hline Değișken & $\begin{array}{c}1 \\
\text { (1 AŞAMALI) }\end{array}$ & $\begin{array}{c}2 \\
\text { (2 AŞAMALI) }\end{array}$ & $\begin{array}{c}3 \\
\text { (1 AŞAMALI) }\end{array}$ & $\begin{array}{c}4 \\
(2 \text { AŞAMALI) }\end{array}$ & Beklenen & Sonuç \\
\hline L.İşsizlik & $0,37 * * *$ & $0,33 * * *$ & $0,37 * * *$ & $0,27 * * *$ & $+/-$ & $\checkmark$ \\
\hline GSYH & $-0,50 * * *$ & $-0,50 * *$ & $-0,37 * *$ & $-0,42 * *$ & - & $\checkmark$ \\
\hline TÜFE & $1,69 * * *$ & $1,70 * * *$ & $1,23 * * *$ & $1,36 * * *$ & $+/-$ & $\checkmark$ \\
\hline Vergi Takozu & $-0,17$ & $-0,14$ & $-0,02$ & 0,01 & $+/-$ & $\checkmark$ \\
\hline Reel Döviz Kuru & $-0,06 * * *$ & $-0,06 * *$ & $-0,07 * * *$ & $-0,07 * * *$ & + & $x$ \\
\hline
\end{tabular}




\begin{tabular}{|c|c|c|c|c|c|c|}
\hline Reel Faiz & $0,02 * *$ & $0,02 *$ & $0,02 * * *$ & $0,02 * *$ & + & $\checkmark$ \\
\hline Ücret Pazarlığ 1 & $-0,07 * * *$ & $-0,08 * *$ & $-0,08 * * *$ & $-0,08 * * *$ & - & $\checkmark$ \\
\hline DYS Girişi & $-0,05$ & $-0,05$ & $-0,05$ & $-0,05$ & - & $\checkmark$ \\
\hline DYS Çıkışı & 0,04 & 0,05 & $0,10 * *$ & $0,12 *$ & $+/-$ & $\checkmark$ \\
\hline İşsizlik Harcaması & $0,23 * * *$ & $0,26 * * *$ & $0,24 * * *$ & $0,25 * * *$ & + & $\checkmark$ \\
\hline Sendikalaşma & $-0,04$ & $-0,08$ & 0,00 & 0,00 & + & $\checkmark$ \\
\hline Patent & $-0,03$ & $-0,02$ & $-0,02$ & $-0,02$ & $+/-$ & $\checkmark$ \\
\hline L.Patent & & & $-0,06 * *$ & $-0,06 * *$ & $+/-$ & $\checkmark$ \\
\hline L2.Patent & & & $-0,0357$ & $-0,04$ & $+/-$ & $\checkmark$ \\
\hline Kukla Değişken & $-0,15 * * *$ & $-0,160 * * *$ & $-0,136 * * *$ & $-0,13 * * *$ & $+/-$ & $\checkmark$ \\
\hline $\mathrm{N}$ & 23 & 23 & 23 & 23 & & \\
\hline Wald & 29578,14 & 18214,83 & 24783,83 & 24826,86 & & \\
\hline AR (1) p & 0,57 & 0,53 & 0,33 & 0,72 & & \\
\hline $\operatorname{AR}(2) \mathrm{p}$ & 0,21 & 0,61 & 0,20 & 0,67 & & \\
\hline Hansen $p$ & 0,08 & 0,08 & 0,34 & 0,34 & & \\
\hline
\end{tabular}

Elde edilen ilk sonuçlara göre (Sütun 1 ve Sütun 2) kontrol değişkenlerinin birçoğunun hem bir aşamalı hem iki aşamalı tahmincilerde açıklama gücünün yüksek olduğu görülmüştür. Bununla birlikte analizin temel amacı olan teknolojik yenilik değişkeninin (Patent) işsizlikle ilişkisinin istatistiki olarak anlamlı olmadığı sonucuna ulaşılmıştır.

Yapılan ilk analiz sonucunda teknolojik yenilik değişkeninin işsizlik oranı ile ilişkisinin istatistiki olarak anlamsız olması, bu ilişkinin varlığını test eden bir hipotez için elde edilmiş önemli bir sonuçtur. Yine de bu ilişkisizliğin yalnızca kısa dönemde yoksa uzun dönemde mi geçerli olduğunun tespit edilmesi, analizden daha kapsamlı sonuç çıkartılmasını sağlayacaktır. Özellikle teknoloji gibi gecikmeli olarak etki yaratabilecek ve kısa süreli veya uzun süreli kalıcı etkiye neden olabilecek değişkenlerde bağımsız değişkenin gecikmeli etkisine de bakılmasının farklı sonuçlar ortaya çıkarabileceği değerlendirilmektedir. Örneğin, yeni ortaya çıkan bir yenilik, yok ettiği işgücü nedeniyle kısa dönem etkisi olarak işsizliği arttırabilecektir. Ancak uzun vadede yeni gelişen teknoloji ile birlikte yeni iş kolları ortaya çıkabilecek ve bu etkiyi ortadan kaldırabilecektir. Hatta uzun dönemde teknolojinin etkisiyle artan verimlilik ve yeni iş kollarının daha fazla olması sebebiyle işsizliği azaltan etkiye dahi rastlanması mümkün olabilecektir.

Feldmann (2013) ve onu takip eden Matuzeviciute vd. (2017) çalışmalarında patentin gecikmeli etkisine bakarak etkinin uzun süreli mi yoksa kısa süreli mi olduğunu değerlendirmiştir. Bu çalışmada da benzer şekilde patentin gecikmeli değerinin etkisine bakılan yeni bir analiz daha yapılmıştır ve bu şekilde bu ilişki ve/veya ilişkisizliğin uzun süreli ve kısa süreli etkisi ayrı ayrı ortaya konulmaya çalışılmıştır. Yapılan yeni analiz sonuçları Tablo 4'ün 
3 ve 4 'üncü sütununda yer almaktadır. Karşılaştırmanın tutarlı olması için model, aynı kontrol değişkenleriyle aynı yöntem ve parametreler kullanılarak yeniden tahmin edilmiştir.

Yapılan ikinci analizde de kontrol değişkenlerinin birçoğunun hem bir aşamalı hem iki aşamalı analizlerde (Sütun 3 ve Sütun 4) açıklama gücünün yüksek olduğu görülmüştür. Analizin temel amacı olan teknolojik yenilik değişkeninin (Patent) işsizlikle ilişkisinin ilk analizdeki sonuçlara paralel olarak her iki yöntemde de istatistiki olarak anlamlı olmadığ sonucuna ulaşılmıştır. Ancak üçlü patent ailesinin bir yıl gecikmeli hali hem bir aşamalı hem iki aşamalı tahmincilerinde istatistiki olarak \%5 anlamlılık düzeyinde anlamlı çıkmıştır. Üstelik bu ilişki, teknolojinin işsizlik üzerinde genel olarak beklenen olumsuz etkisinin aksine işsizlik oranı ile negatif ilişkili olarak bulunmuştur. Başka bir deyişle teknolojinin 1 yıl gecikmeli etkisinde her \%1'lik artışın işsizliği \%0,06 azalttığı sonucuna ulaşılmıştır. Ancak 2 yıl gecikmeli ilişkiye baktığımızda bu etkinin yeniden ortadan kaybolduğu yani etkinin 1 yıl sonra gecikmeli olarak ortaya çıktığı ve kısa süreli geçici bir etki olduğu görülmüştür. Bu bağlamda teknolojinin işsizlik üzerinde kısa süreli küçük ve olumlu bir etki yaptığg ve bu etkinin ikinci y1l sonunda ortadan kaybolmaya başladığı yani geçici bir etki olduğu görülmektedir.

Elde edilen sonuçların birbiri ile tutarlı olması ve kontrol değişkenlerin işaretlerinin aynı yönlü olmasından dolayı yalnızca en anlamlı tahmincilerin elde edildiği S-GMM iki aşamalı tahmincilerinin son değerleri ve işaretleri (Sütun 4) yorumlanmıştır. Bu kapsamda kontrol değişkenlerinden:

- Kişi başına düşen GSYH'nın (g) literatürde beklenen işareti taşıdığı (-), \%5 anlamlılık düzeyinde istatistiki olarak anlamlı olduğu ve kişi başına düşen GSYH'daki her \%1'lik artışın işsizliği \%0,42 azalttığ1;

- Enflasyon göstergesi olarak alınan tüketici fiyat endeksinin (fe) işsizlik oranı ile ilişkisi pozitif yönlü ve \%1 anlamlılık düzeyinde istatistiki olarak anlamlı bulunmuştur. Philips eğrisinde öngörülen ters yönlü enflasyon-işsizlik ilişkisine rastlanılmamıştır. Ancak sonuçlar bu ilişkinin geçerliliğini yitirdiğine dair literatürde mevcut birçok ampirik bulgu (Alisa 2015; Bayrak ve Kanca 2013; Kuştepeli 2005) ile uyumludur. Bulgulara göre, TÜFE'deki her \%1'lik artışın işsizliği \%1,36 arttırdı̆̆ı;

- İşçinin ücretindeki vergi ve sigorta yükünü temsil eden vergi takozu (vt) ile işsizlik oranı ilişkisinin pozitif yönlü bulunduğu ancak istatistiki olarak anlamlı olmadığı;

- Reel döviz kuru artışının (d) işsizlik oranı ile ilişkisi negatif yönlü bulunmuştur ve bu ilişki \%1 anlamlılık düzeyinde istatistiki olarak anlamlıdır. Literatürde genel olarak reel döviz kuru artışının işsizliği arttırması beklenirken bu analizde reel döviz kurundaki her \%1'lik artışın işsizliği \%0,07 azaltacağı sonucuna ulaşıldığı ve bu etkinin çok küçük olduğu; 
- Reel faiz oranının (f) literatürde beklenen işareti taşıdığı (+) ve \%10 anlamlılık düzeyinde istatistiki olarak anlamlı olduğu, reel faiz oranındaki her \% 1 'lik artışın işsizliği \%0,02 arttırdığı;

- Ücret pazarlığı koordinasyonunun (k) literatürde beklenen işareti taşıdığı (-) ve \%1 anlamlılık düzeyinde istatistiki olarak anlamlı olduğu, her \%1'lik artışın işsizliği \%0,08 azalttığ1;

- Doğrudan yabancı sermaye girişlerinin (sg) işsizlik oranı ile ilişkisinin literatüre uyumlu ve beklenen yönlü (-) olduğu ancak bu ilişkinin istatistiki olarak anlamlı olmadığı;

- Doğrudan yabancı sermaye çıkışlarının (sç) işsizlik oranı ile ilişkisinin pozitif yönlü olduğu, \%10 anlamlılık düzeyinde istatistiki olarak anlamlı olduğu ve her \%1'lik artışın işsizliği $\% 0,12$ arttırdı ğ

- Kamu işsizlik harcamasının (ih) literatürde beklenen işareti taşıdığı (+) ve \%1 anlamlılık düzeyinde istatistiki olarak anlamlı olduğu, kamu işsizlik harcamalarındaki her \%1'lik artışın işsizliği \%0,25 $\operatorname{arttırdı~} \breve{g} 1$;

- Sendikalaşma oranı ile işsizlik oranı ilişkisinin literatüre uyumlu olarak (+) bulunduğu ancak bu sonucun istatistiki olarak anlamlı olmadığı;

- 2008 y1lı için oluşturulan kriz kukla değişkeninin \%1 anlamlılık düzeyinde istatistiki olarak anlamlı olduğu görülmektedir.

GMM analizlerinde elde edilen sonuçların istikrarlı ve güvenilir kabul edilebilmesi için yapılması zorunlu olan testler bulunmaktadır. Arellano ve Bond (1991), Arellano ve Bover (1995) ve Blundell ve Bond'a (1998) göre GMM analizlerinde, araç değişkenlerin geçerliliği testi ve ikinci dereceden otokorelasyon testi yapılması zorunludur. Araç değişkenlerden yararlanan GMM analizinin geçerli olması için araçların dışsal olması en önemli varsayımdır. Hansen (1982) J testi ve Sargan (1958) testi, araç değişkenler için aşırı tanımlama kısıtlamalarının geçerli olup olmadığını test eden yaygın yöntemlerdir (Arellano 2003, 193; Roodman 2019a, 141; 2009b, 97). Aşı1ı tanımlama kısıtlamalarının geçerli olması, araç değişkenlerin dışsal olduğunu ve kalıntıların açıklayıcı değişkenlerle korelasyonsuz olduğunu göstermektedir (Tatoğlu, 2018, 148).

$\mathrm{Bu}$ analizde araç değişkenlerin geçerliliğini test etmek için Hansen (1982) J testi kullanılmıştır. $\mathrm{Bu}$ testte $\mathrm{H}_{\mathrm{o}}$ hipotezi “Aşırı tanımlama kısıtlamaları geçerlidir" şeklinde kurulmuştur. Test sonucunda $\mathrm{H}_{\mathrm{o}}$ hipotezi reddedilememektedir. Dolayısıyla aşırı tanımlama kısıtları geçerlidir yani değişkenler dışsaldır. Kullanılan araç değişkenlerin dışsal olması kalıntıların açıklayıcı değişkenlerle korelasyonsuz olduğunu göstermektedir (Tatoğlu 2018, 148). Test sonucuna göre, modelin araç değişkenler açısından uygun olduğu ve sonuçların güvenilir olduğu anlaşılmaktadır. Ayrıca Hansen J testinde Roodman (2009b) tarafından 
önerilen ideal değerlere yakın sonuçlar elde edildiği görülmektedir (Hansen $\mathrm{J}$ testi p değeri: $0,34)$.

Sonuçların güvenilir olması için yapılması gerekli olan bir değer test, otokorelasyon testidir. $\mathrm{Bu}$ test için $\mathrm{H}_{\mathrm{o}}$ hipotezi “Otokorelasyon yoktur” şeklinde kurulmuştur. Birinci dereceden (AR1) ve ikinci dereceden (AR2) otokorelasyon sonuçlarına ayrı ayrı bakılması gerekmektedir. GMM analizlerinde AR1 için hipotezin reddedilmesi beklenen bir sonuçtur ve genellikle negatif otokorelasyon ile karşılaşılmaktadır. Ancak AR2 hipotezinin reddedilmemesi yani ikinci dereceden otokorelasyon olmaması önemlidir (Mileva 2007, 7). Yapılan test sonucunda hem AR1 için hem AR2 için $\mathrm{H}_{\mathrm{o}}$ hipotezi reddedilememektedir. Dolayısıyla modelde birinci ve ikinci dereceden otokorelasyon yoktur (AR1 $\mathrm{p}=0,72$ ve AR2 $\mathrm{p}=0,67$ ). Ayrica analizde kullanılan Wald testi istatistiği de anlamlıdır $(24826,86)$ ve modelin bir bütün olarak anlamlı olduğunu göstermektedir.

Gelişmekte olan teknolojiler çeşitli riskler ve belirsizlikler taşımaktadır. İnternet, sanal oyunlar ve sosyal ağların sağladığı zevk tuzakları teknoloji bağımlılığında sadece buz dağının görünen yüzüdür. Beyin-bilgisayar bağlantısı sağlayan arayüzler, implantlar, nöral bağlantı arayüzleri, nesnelerin interneti, biyomühendislik ve genetik bilimleri ve daha birçok çığır açıcı ve hayal gücünü bile zorlayan teknolojilerle karşı karşıya olduğumuz bir dönemi yaşamaktayız. Teknoloji üstel ve kontrolsüz bir hızla büyümektedir. Üstelik teknolojik gelişmeler artık durdurulamaz gibi görünmektedir. Çünkü insanoğlunun yeni bir şeyler deneme ve başarma güdüsü doğası gereğidir. Gelecekte hangi teknoloji ve buluşlarla karşılaşacağımız artık hayal gücümüzün sınırlarını dahi aşmaktadır. Yakın zamanda bilim-kurgu filmlerinde görmeye alıştığımız birçok teknoloji, gündelik hayatımızın içerisine yerleşmiş durumdadır.

Teknoloji, kas gücü gerektiren işler başta olmak üzere rutin tekrarlanabilen işleri insanlardan devralmaktadır. Ancak artan verimlilik sayesinde yaşanan maliyet azalması ile daha etkin piyasalar ortaya çıkmaktadır. Bunun yanı sıra yeni makinelerin tasarımı, üretimi, yenilenmesi, geliştirilmesi ve bakımı gibi birçok yeni sektör ve yeni iş ortaya çıkmaktadır. $\mathrm{Bu}$ durum kaybedilen işlerin önemli derecede telafi edilmesine katkıda bulunmaktadır. Schumpeter' in yaratıcı yıkım olarak adlandırdığı sürecin bugüne kadar sağlıklı işlediği ve kalıcı işsizlik anlamında uzun ve belirgin bir dönemin yaşanmadığı görülmektedir.

\section{Sonuç ve Politika Önerileri}

Bu çalışmada 2005-2018 yıllarına ait ve AB ülkeleri ile Türkiye'yi kapsayan veri seti ile teknoloji ve işsizlik ilişkisi, panel veri yöntemi ile analiz edilmektedir. Panel veri analizinde, 
Arellano ve Bover/ Blundell ve Bond "S-GMM" yöntemi bir ve iki aşamalı tahmincileri kullanılmıştır.

$\mathrm{Bu}$ analiz ile teknolojinin işsizlik üzerinde olumsuz etki yapacağına dair genel ön yargı çürütülmektedir. Bununla birlikte telafi mekanizmaları ve yaratıcı yıkım süreci ile teknolojinin az da olsa işsizliği azalttığı bulgusuna ulaşılmıştır. Ancak uzun vadeli etkilere bakıldığında teknoloji ve işsizlik arasında istatistiki bir ilişki olmadığı görülmektedir. Keynes’in ortaya attığı kalıcı teknolojik işsizlik tarihin hiçbir döneminde yaşanmamıştır ve teknoloji ne kadar büyük bir etki yaratsa da istihdam bir şekilde dengelenmiştir. Keynes’ten günümüze dünya genelinde yaşanan işsizlik oranlarına bakıldığında da kriz dönemlerinin dışında teknolojik devrimlerden kaynaklı belirgin bir değişime rastlanmamaktadır. Elde edilen ampirik bulgular da bu durumu destekler niteliktedir ve son yirmi yılda teknolojinin etkisiyle kalıcı bir işsizlik yaşanmadığını istatistiki bulgularla ortaya koymaktadır.

Kontrol değişkenleri ile ilgili açıklamalardan da anlaşılacağ üzere reel döviz kuru haricinde tüm kontrol değişkenlerinde literatürle uyumlu bulgular elde edilmiştir. Analiz 23 ülke ve 10 kontrol değişkeninden oluşan kapsamlı bir model olmasına rağmen değişkenlerin tamamına yakınında istatistiki olarak anlamlı ve beklenen yönde bulgular elde edilmesinin literatüre önemli bir katkı sağlayacağı değerlendirilmektedir.

Teknolojinin hızının ve etkisinin gelecekte ne olacağını şimdiden kestirmek olanaksızdır ancak tarih şunu göstermiştir ki insan işgücü değişen şartlara uyum sağlamakta ve teknoloji ile değişen ve yeni ortaya çıkan iş dünyasında yeni işler bulmaya devam etmektedir. Teknolojinin sosyal ve etik değerler açısından bakıldığında kaygı verici bir potansiyel barındırdığını kabul etmek yerinde olacaktır. Ancak eldeki veriler ışığında işsizlik anlamında teknoloji kaynaklı büyük bir endişeye yer olmadığı değerlendirilmektedir. Bununla birlikte otomasyon sürecinin artarak devam edeceğini, günümüz becerilerinin birçoğunun gelecekte yeterli olmayacağını ve yeni beceriler geliştirilmesi gerektiğini kabul etmek son derece yerinde olacaktır.

Otomasyonla birlikte birçok işin ve görevin doğası değişecektir. Ancak diğer taraftan daha etkin piyasalar ve daha düşük maliyetler ortaya çıkmaktadır. Kaybolan işlerin yerine teknolojinin getirdiği yeni işler ve sektörler doğmaktadır. Brynjolfsson ve McAfee (2014), çalışanlara makineler karşısında yarışmak yerine makinelerle birlikte yarışmayı öğrenmelerini tavsiye etmektedir. Teknolojinin durdurulamaz olduğu kabul edildiğinde bu çok yerinde bir tavsiye olarak görülmektedir.

Gelecekte yapılacak çalışmalarda farklı teknoloji değişkenleri ile teknoloji ve işsizlik ilişkisini analiz eden çalışmalar tavsiye edilmektedir. Örneğin farklı bir uluslararası patent sınıflandırması, endüstriyel robot sayıları, küresel yenilik endeksi gibi değişkenler kullanılarak 
yapılan analizler literatüre önemli katkılar sağlayacaktır. Bununla birlikte teknolojinin toplumsal ve sosyal etkilerine yönelik çalışmalar yapılması, teknolojinin bilimsel etiğinin açıkça tartışılması ve teknolojinin regülasyonu için devlet müdahalesinin tartışılmasının yararlı olacağı değerlendirilmektedir.

$\mathrm{Bu}$ çalışmada analiz edilen teknoloji-işsizlik ilişkisi, teknolojinin iktisadi etkilerinin yalnızca bir boyutudur. Teknolojinin diğer iktisadi etkilerine ilişkin ampirik çalışmaların yapılması literatürdeki boşluğu doldurmak için elzemdir. Örneğin, beceri yanlı teknolojik değişim, rutin yanlı teknolojik değişim ve işgücü kutuplaşmasına ilişkin ampirik çalışmaların literatüre önemli katkılar sağlayacağı değerlendirilmektedir. Ayrıca teknolojinin etkilerini dengeleyen telafi mekanizmalarının etkilerini ayrı ayrı analiz eden çalışmalar literatürde yok denecek kadar azdır ve bu tür çalışmaların yapılmasının yararlı olacağı değerlendirilmektedir. 


\section{KAYNAKÇA}

Abor, J. \& Harvey, S.K. 2008. "Foreign Direct Investment and Employment: Host Country Experience." Macroeconomics and Finance in Emerging Market Economies, 1 (2): 213-225.

Adanu, K. 2005. “A Cross-province Comparison of Okun's Coefficient for Canada.” Applied Economics, 37 (5): 561-570.

Aguilera, A. \& Barrera, M.G.R. 2016. "Technological Unemployment: an Approximation to the Latin American Case.” AD-Minister, 29: 59-78.

Alisa, M. 2015. "The Relationship between Inflation and Unemployment: A Theoretical Discussion about the Phillips Curve." Journal of Business and Economics, 3 (2): 89-97.

Anderson, T.W. \& Hsiao, C. 1981. "Estimation of Dynamic Models with Error Components." Journal of the American Statistical Association, 76: 598-606.

Anderson, T.W. \& Hsiao, C. 1982. "Formulation and Estimation of Dynamic Models u-Using Panel Data." Journal of Econometrics, 18: 47-82.

Arellano, M. 2003. Panel Data Econometrics. Oxford: Oxford University Press.

Arellano, M. \& Bond, S. 1991. "Some Tests of Specification for Panel Data: Monte Carlo Evidence and an Application to Employment Equations." Review of Economic Studies, 58: 277-297.

Arellano, M. \& Bover, O. 1995. "Another Look at the Instrumental Variables Estimation of Error Component Models." Journal of Econometrics, 68: 29-51.

Baccaro, L. \& Rei, D. 2007. "Institutional Determinants of Unemployment in OECD Countries: Does the Deregulatory View Hold Water?” International Organization, 61 (3): 527-569.

Bakhshi, Z. \& Ebrahimi, M. 2016. "The Effect of Real Exchange Rate on Unemployment." Marketing and Branding Research, 3 (2016): 4-13.

Baltagi, B.H. 2005. Econometric Analysis of Panel Data. 3rd Edition. New York: John Wiley \& Sons Inc.

Barba Navaretti, G. \& Castellani, D. \& Disdier, A.C. 2010. "How does Investing in Cheap Labour Countries Affect Performance at Home? Firm-level Evidence from France and Italy." Oxford Economic Papers, 62: 234260.

Bayrak, M. \& Kanca, O.C. 2013. “Türkiye'de Philips Eğrisi Üzerine Bir Uygulama.” Eskişehir Osmangazi Üniversitesi IIBBF Dergisi, 8 (3): 97-115.

Blanchard, O. \& Wolfers, J. 2000. "The Role of Shocks and Institutions in the Rise of European Unemployment: The Aggregate Evidence." The Economic Journal, 110 (462): 1-33.

Blundell, R. \& Bond, S. 1998. "Initial Conditions and Moment Restrictions in Dynamic Panel Data Models." Journal of Econometrics, 87: 115-143.

Blundell, R. \& Bond, S. \& Windmeijer, F. 2000. "Estimation in Dynamic Panel Data Models: Improving on the Performance of the Standard GMM Estimator." Advances in Econometrics, 15: 53-91.

Bogliacino, F. \& Vivarelli, M. 2012. "The Job Creation Effect of R\&D Expenditures.” Australian Economic Papers, 51 (2): 96-113.

Bond, S. \& Bowsher, C. \& Windmeijer. F. 2001. "Criterion-based Inference for GMM in Autoregressive Panel Data Models." Economic Letters, 73: 379-388.

Brynjolfsson, E. \& McAfee, A. 2014. İkinci Makine Çă̆l: Akıllı Teknolojiler Devrinde Çalışma, İlerleme ve Refah (Orj.The Second Machine Age: Work, Progress and Prosperity in a Time of Brilliant Technologies). Çev. L. Göktem. 2018. İstanbul: Türk Hava Yolları Yayınları adına Optimist Yayınları.

Cang, Y. 2017. "A Deep Dive into Technological Unemployment: A State-Level Analysis on the Employment Effect of Technological Innovations", Senior Thesis, Claremont McKenna College.

Chang, S.C. 2007. "The Interactions Among Foreign Direct Investment, Economic Growth, Degree of Openness and Unemployment in Taiwan." Applied Economics, 39 (13): 1647-1661

Driffield, N. \& Love, J. H. \& Taylor, K. 2009. "Productivity and Labour Demand Effects of Inward and Outward Foreign Direct Investment on UK Industry." The Manchester School, 77: 171-203.

Elia, S. \& Mariotti, I. \& Piscitello, L. 2009. "The Impact of Outward FDI on the Home Country's Labour Demand and Skill Composition.” International Business Review, 18: 357-372.

Evangelista, R. \& Guerrieri, P. \& Meliciani, V. 2014. "The Economic Impact of Digital Technologies in Europe." Economics of Innovation and New Technology, 23 (8): 802-824.

Federico, S. \& Minerva, G. A. 2008. "Outward FDI and Local Employment Growth in Italy.” Review of World Economics, 144: 295-324.

Feldmann, H. 2013. “Technological Unemployment in Industrial Countries.” Journal of Evolutionary Economics, 23: $1099-1126$.

Flanagan, R. J. 1999. "Macroeconomic Performance and Collective Bargaining: An International Perspective." Journal of Economic Literature, 37: 1150-1175.

Fraile, M. \& Ferrer, M. 2005. "Explaining the Determinants of Public Support for Cuts in Unemployment Benefits Spending across OECD Countries.” International Sociology, 20 (4): 459-481. 
Frenkel, R. \& Ros, J. 2006. "Unemployment and the real exchange rate in Latin America." World Development, 34 (4): 631-646.

Gregory, T. \& Salomons, A. \& Zierahn, U. 2016. "Racing with or Against the Machine? Evidence from Europe." SSRN Electronic Journal, Discussion Paper No. 16-053.

Hansen, L.P. 1982. "Large Sample Properties of Generalized Method of Moments Estimators, Econometrica, 50 : 1029-1054.

Hauk, W.R. \& Wacziarg, R. 2009. “A Monte Carlo Study of Growth Regressions.” Journal of Economic Growth, 14: 103-147.

Heijs, J. \& Diaz, G.A. \& Reyes, D.M. 2019. “Impact of Innovation on Employment in Quantitative Terms: Review of Empirical Literature Based on Microdata.” MPRA, Paper No. 95326.

Hijzen, A. \& Jean, S. \& Mayer, T. 2011. "The Effects at Home of Initiating Production Abroad: Evidence From Matched French Firms." Review of World Economics, 147: 457-483.

Hsiao, C. 2003. Analysis of Panel Data. Cambridge: Cambridge University Press.

Kangasharju, A. \& Tavera, C. \& Nijkamp, P. 2012. "Regional Growth and Unemployment: The Validity of Okun's Law for the Finnish Regions." Spatial Economic Analysis, 7 (3): 381-395.

Keane, M.P. \& Runkle, D.E. 1992. "On the Estimation of Panel-Data Models With Serial Correlation When Instruments Are Not Strictly Exogenous.” Journal of Business and Economic Statistics, 10: 1-9.

Krousie, C. 2018. "Technological Unemployment in the United States: A State-Level Analysis," Major Themes in Economics, 20 (6): 87-101.

Kuştepeli, Y. 2005. "A Comprehensive Short-run Analysis of a (possible) Turkish Phillips Curve.” Applied Economics, 37: 581-591.

Layard, R. \& Nickell, S. 1985. "The Causes of British Unemployment.” Natl Inst. Econ. Rev., 111: 62-85.

Lee, J. 2000. "The Robustness of Okun's Law: Evidence From Oecd Countries.” Journal of Macroeconomics, 22 (2): 331-356.

Masso, J. \& Varblane, U. \& Vahter, P. 2008. "The Effect of Outward Foreign Direct Investment on Home-Country Employment in a Low-Cost Transition Economy." Eastern European Economics, 46: 25-59.

Matuzeviciute, K. \& Butkus, M. \& Karaliute, A. 2017. "Do Technological Innovations Affect Unemployment? Some Empirical Evidence from European Countries." Economies, 5 (48): 1-19.

Mileva, E. 2007. Using Arellano-Bond Dynamic Panel GMM Estimators in Stata. New York: Fordham University.

Nickell, S. 1981. "Biases in Dynamic Models with Fixed Effects." Econometrica, 49: 1417-1426.

Nickell, S. \& Nunziata, L. \& Ochel, W. 2005. "Unemployment in the OECD Since the 1960s. What Do We Know?" The Economic Journal, 115 (500): 1-27.

Okun, A. 1962. "Potential GNP: Its Measurement and Significance." Proceedings of the Business and Economic Statistics Section of the American Statistical Association, 7 (1): 89-104.

Onodugo, V. A., et al. 2017. "Does Public Spending Affect Unemployment in an Emerging Market." Risk Governance \& Control: Financial Markets \& Institutions, 7 (1): 32-40.

Phillips, A. W. 1958. "The Relationship between Unemployment and the Rate of Change of Money Wage Rates in the United Kingdom 1861-1957." Economica, 25: 283-299.

Pierdzioch, C. \& Rülke, J-C-Stadtmann, G. 2011. "Do Professional Economists’ Forecasts Reflect Okun's Law? Some Evidence for the G7 Countries." Applied Economics, 43 (11): 1365-1373.

Pini, P. 1995. "Economic Growth, Technological Change and Employment: Empirical Evidence for a Cumulative Growth Model with External Causation for Nine OECD Countries: 1960-1990.” Structural Change and Economic Dynamics, 6: 185-213.

Roodman, D. M. 2009a. "A note on the Theme of Too Many Instruments." Oxford Bulletin of Economics and Statistics, 71: 135-158.

Roodman, D.M. 2009b. "How to Do xtabond2: An Introduction to "Difference" and "System" GMM in Stata." The Stata Journal, 9 (1): 86-136.

Samuelson, P. A. \& Solow R.M. 1960. “Analytical Aspects of Anti-Inflation Policy.” American Economic Review, 50: 177-94.

Sargan, J. D. 1958. The Estimation of Economic Relationships Using Instrumental Variables.” Econometrica, 26 : 393-415.

Sharma, A. \& Cardenas, O. 2019. "The Labor Market Effects of FDI: A Panel Data Evidence from Mexico." International Economic Journal: 1-17.

Simonetti, R. \& Taylor, K. \& Vivarelli, M. 2000. Modelling The Employment Impact of Innovation, (Ed. Pianta ve Vivarelli). in The Employment Impact of Innovation: Evidence and Policy, Routledge: 26-46.

Sinclair, P.J.N. 1981. "When will Technical Progress Destroy Jobs?” Oxf. Econ. Pap., 31: 1-18.

Soskice, D. 1990. "Wage Determination: The Changing Role of Institutions in Advanced Industrialized Countries." Oxford Review of Economic Policy, 6: 36-61.

Sögner, L. 2001. "Okun's Law Does the Austrian Unemployment-GDP Relationship Exhibit Structural Breaks?" Empirical Economics, 26: 553-564. 
Sögner, L. \& Stiassny, A. 2002. "An Analysis on the Structural Stability of Okun's Law-A Cross-Country Study." Applied Economics, 34 (14): 1775-1787.

Tancioni, M. \& Simonetti, R. 2002. "A Macroeconometric Model for the Analysis of the Impact of Technological Change and Trade on Employment." Journal of Interdisciplinary Economics, 13: 185-221.

Tatoğlu, Y. F. 2018. Illeri Panel Veri Ekonometrisi: Stata Uygulamalı. 3. Bask1. İstanbul: Beta Yayıncılık.

Vandaele, K. 2006. "A Report from the Homeland of the Ghent System: The Relationship Between Unemployment and Trade Union Membership in Belgium Transfer." European Review of Labour and Research, 12 (4): 647-657.

Visser, J. 2019. ICTWSS Database. Version 6.0. Amsterdam: Amsterdam Institute for Advanced Labour Studies (AIAS), University of Amsterdam. June 2019.

Vivarelli, M. 1995. The Economics of Technology and Employment: Theory and Empirical Evidence. Lyme: Edward Elgar.

Windmeijer, F. 2005. "A Finite Sample Correction for the Variance of Linear Efficient Two-Step Gmm Estimators." Journal of Econometrics, 126: 25-51. 